\title{
Cathodoluminescence study of silicon oxide/silicon interface
}

\author{
(c) M.V. Zamoryanskayaף, V.I. Sokolov
}

loffe Physicotechnical Institute, Russian Academy of Sciences, 194021 St. Petersburg, Russia

\section{(Получена 12 сентября 2006 г. Принята к печати 3 октября 2006 г.)}

\begin{abstract}
In this paper the local cathodoluminescence method was used to study characteristics of $\mathrm{SiO}_{2} / \mathrm{Si}$ interface, a change of its properties during oxidation and an influence of the type of silicon conductivity on the properties of $\mathrm{SiO}_{2} / \mathrm{Si}$ interface. This research shows that the first phase of silicon oxidation is formation of amorphous silicon layers on the silicon surface and the appearance of silicon clusters in the natural silicon oxide. Cathodoluminescence gives a possibility for founding the presence of point defects in silicon oxide and silicon and for studying the distribution of such defects on the surface and at the depth.
\end{abstract}

PACS: 68.35.Dv, 78.60.Hk, 78.66.Db

\section{Introduction}

The quality of $\mathrm{SiO}_{2} / \mathrm{Si}$ interface plays the main role in the technological process of formation of different types of structures on silicon. That is why different diagnostic methods are used to characterize this interface, to study the process of its formation and to find the optimal conditions for that. In this paper we used the method of local cathodoluminescence for $\mathrm{SiO}_{2} / \mathrm{Si}$ investigation. Local cathodoluminescence gives a possibility for showing the presence of point defects in silicon oxide and silicon, for studying the distribution of such defects on the surface and inside the structure. Very important advantage of this method is the possibility to observe optical transitions of electrons from high energy levels, which need to be exited with the energy more than $5-6 \mathrm{eV}$ (vacuum UV). This is very important for wide-gap materials as silicon oxide. In addition, the method of local cathodoluminescence permits to use very high level of excitation. (We can use the energy of electrons about $1-30 \mathrm{keV}$ and density of electron beam current $0.01-1000 \mathrm{nA} / \mu \mathrm{m}^{2}$.) This gives the possibility for saturating the emission energy levels and as a result for observing the emission from higher energy levels. At the same time it is very useful for interpretation the nature of luminescence of different materials. In this paper we used all these possibilities of the local cathodoluminescent method to study characteristics of $\mathrm{SiO}_{2} / \mathrm{Si}$ interface, the change of its properties during oxidation and the influence of technological conditions on the properties of $\mathrm{SiO}_{2} / \mathrm{Si}$ interface.

\section{Method}

All cathodoluminescence (CL) measurements were performed using an originally made system including two spectrometers, for ultraviolet (UV) and visible range $(1.6-5.5 \mathrm{eV})$ and near infrared (IR) range $(1.0-1.9 \mathrm{eV})$. This system gives a possibility to obtain spectra in time-

\footnotetext{
I E-mail: zam@mail.ioffe.ru
}

resolved mode and to measure time dependence of emission bands with resolution $0.1 \mu \mathrm{s}$. This cathodoluminescence system is connected with microprobe analyzer "Camebax“ (Cameca) [1].

To study the cathodoluminescence properties near the interface we used three ways. The first way included preparing of wedge of silicon oxide on silicon by chemical etching (Fig. 1). Cathodoluminescent spectra were obtained along silicon oxide wedge from place to place. The energy of electron beam was $1 \mathrm{keV}$. Under these conditions electron beam penetration is about $20-30 \mathrm{~nm}$ and the depth resolution of such method depends on the value of the wedge angle. But in this case it is very difficult to determine the real thickness of silicon oxide in the position where the spectrum is obtained.

The second way was preparation of steps with different thickness $(10,20 \mathrm{~nm})$ by chemical etching. In this instance it is easy to know the thickness of silicon oxide, but depth resolution depends on the technical possibility of preparing the steps with different height.

The last way we used was changing the energy of electron beam. The calculation shows [2] that the penetration of electron beam with energy $1 \mathrm{keV}$ is $\sim 20 \mathrm{~nm}, 5 \mathrm{keV}-$ $250 \mathrm{~nm}, 10 \mathrm{keV}-0.5 \mu \mathrm{m}$. For the thermal films with thickness $0.4 \mu \mathrm{m}$ the electron beam with energy $5 \mathrm{eV}$ excites only silicon oxide. If the energy of electron beam is $10 \mathrm{keV}$ the area of cathodoluminescence generation includes the $\mathrm{SiO}_{2} / \mathrm{Si}$ interface and silicon substrate. In this case we have low depth resolution, but we do not use special sample preparation.

\section{Results and discussions}

\subsection{The nature of cathodoluminescence bands in silicon oxide-silicon system}

It is well known that cathodoluminescence spectra of thermal silicon oxide films are characterized by two bands in visible range: orange with maximum of intensity at $1.9 \mathrm{eV}$ and blue at $2.7 \mathrm{eV}$. These bands are related to intrinsic 


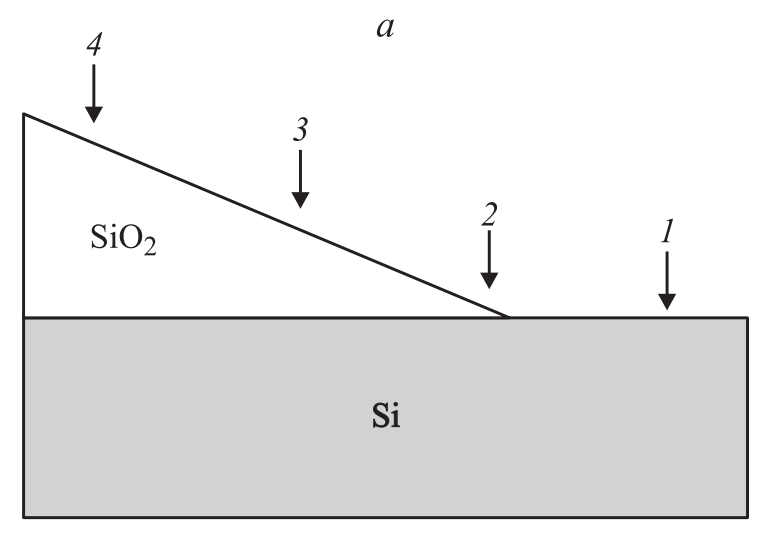

$b$
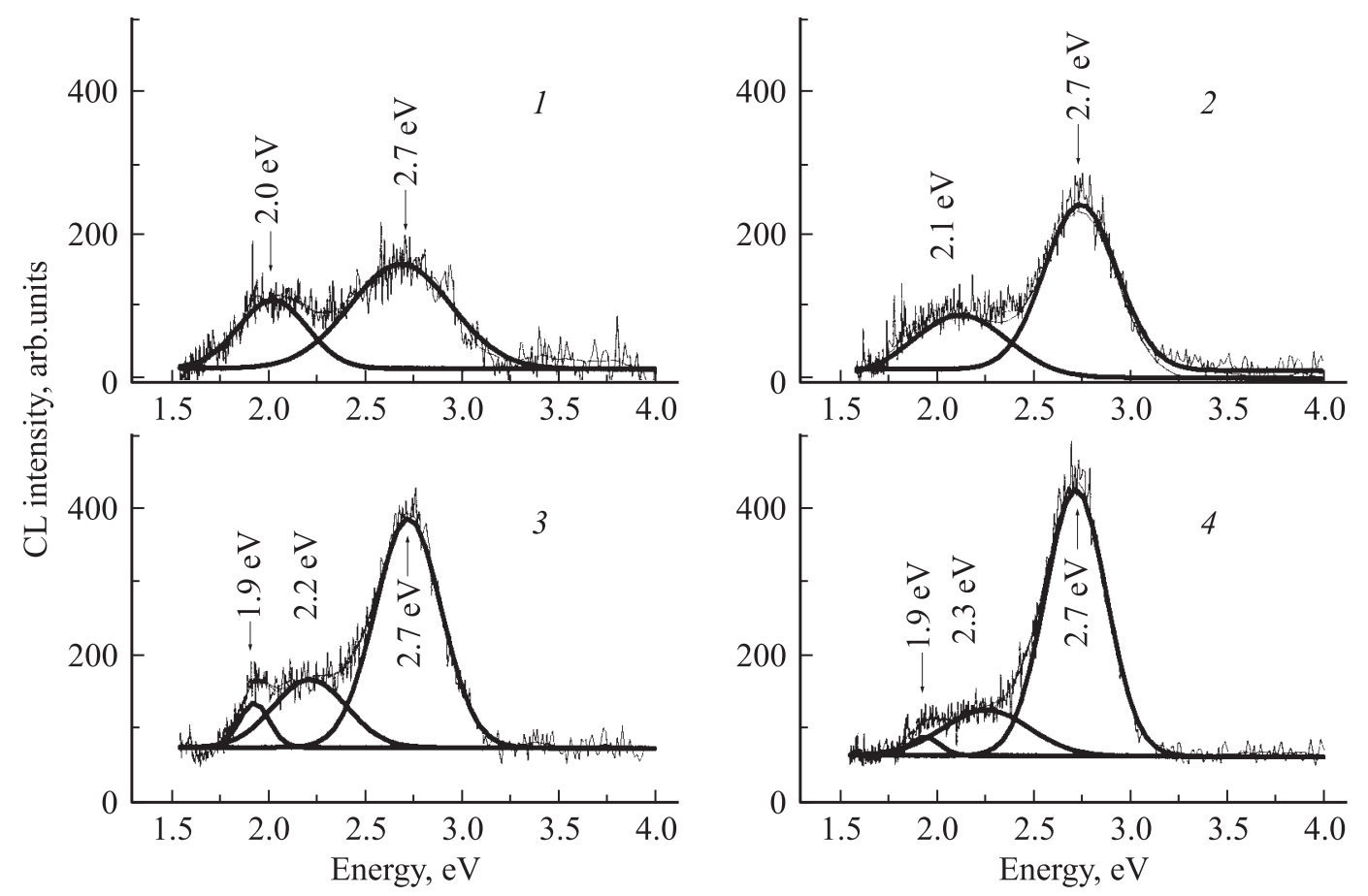

Figure 1. Silicon oxide wedge on silicon $(a)$ and cathodoluminescence spectra obtained on the wedge of silicon oxide film $(b)$. 1 - spectrum of natural silicon oxide on the silicon substrate; 2 - spectrum obtained on the beginning of silicon oxide wedge; 3 - spectrum obtained at $0.1 \mu \mathrm{m}$ distance from the interface; 4 - spectrum obtained at $0.3 \mu \mathrm{m}$ distance from the interface.

point defects in silica: non-bridged oxygen $(1.9 \mathrm{eV})$ and twofold coordinated silicon $(2.7 \mathrm{eV})[3,4]$. The study of different silicon oxide-silicon systems (thick thermal silicon oxide films, bulk silica, non-stoichiometric silicon oxide films [5-7]) showed the presence of green band with maximum of intensity at $2.0-2.4 \mathrm{eV}$. As a rule this band looks like an arm of blue band $(2.7 \mathrm{eV})$. It is better to measure this band in time-resolved mode. This method is very effective in this case because the decay time of the blue band at $2.7 \mathrm{eV}$ is slower compared with the green band. That is why it is possible to find optimal time regime (by changing the time of exposition and the delay time) to separate the blue and the green bands (Fig. 2). Our study showed that the spectral position of this band and its full width on the half of maximum (FWHM) depend on the samples. In „pure“ stoichiometric silicon oxide this band has spectral position $2.3-2.4 \mathrm{eV}$ and its FWHM is $\sim 0.3 \mathrm{eV}$. This band has a ,red“ shift $(2.0-2.2 \mathrm{eV})$ for nonstoichiometric silicon oxide films (with oxygen deficit), near the interface $\mathrm{SiO}_{2} / \mathrm{Si}$ and for silicon oxide films including silicon clusters. Its FWHM can vary from 0.3 to $0.8 \mathrm{eV}$. The main characteristics of the cathodoluminescence bands are given in Table 1.

In accordance with our results, the green band is related to oxygen deficit too. It may be the silicon-silicon bond [8] Formation of long silicon chains or rings in silica can lead 

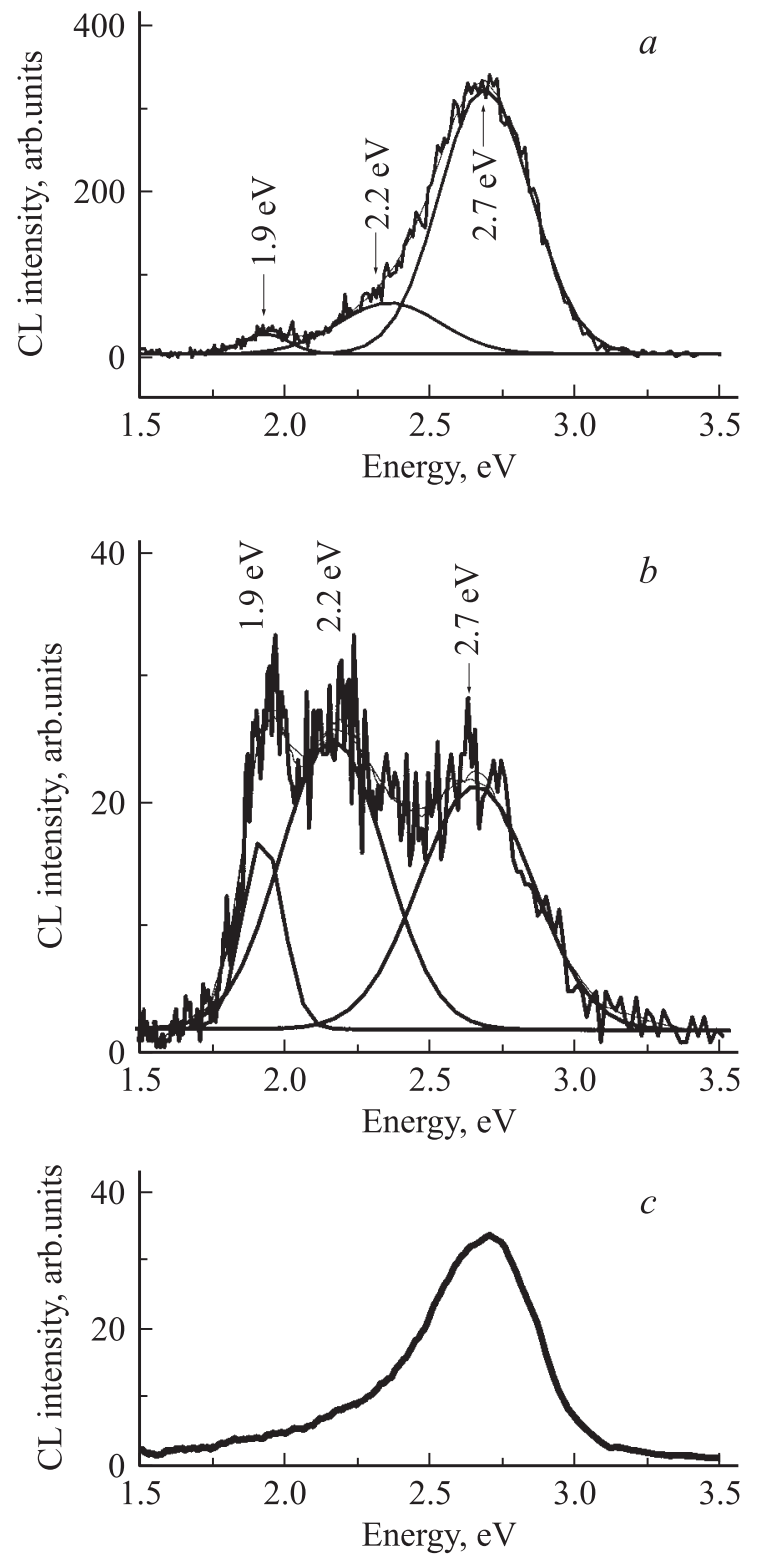

Figure 2. Cathodoluminescence spectra of silica: $a-$ emission was exited without interruption of electron beam; $b, c-$ spectra were obtained in time-resolved mode during the exiting by an electron beam with exposition $20 \mathrm{~ms}(b)$ and after delay of electron beam in $20 \mu \mathrm{s}(c)$.

to „red" shift of emission band [9]. In this case the FWHM of the band depends on the length variation of such silicon chains in silica. Because of this, spectral characteristics of the green band give important information about the quality of silicon oxide-silicon interface.

Cathodoluminescence spectra in near IR range give information about point defects in silicon near the interface. The silicon substrate under the thick silicon oxide film at room temperature is characterized by week luminescence band with maximum intensity at $\sim 1.17 \mathrm{eV}$ (Fig. 3). In cathodoluminescence spectra of amorphous silicon and porous silicon with a great amount of amorphous silicon phase the bands at $1.26-1.35 \mathrm{eV}$ are observed. The same band was reiterated from the silicon surface and we related it to the formation of amorphous silicon layers on the silicon substrate. The amorphous layers can appear as a result of solution of oxygen in surface layers of silicon.

The next very important bands in IR region are related to silicon clusters. The maximum of intensity of these bands is observed at $1.4-1.9 \mathrm{eV}[10,11]$. The spectral position and FWHM of these bands depend on silicon cluster size, size distribution and its crystallinity. The main cathodoluminescence bands of silicon oxide-silicon in visible and near IR region are shown in Table 2.
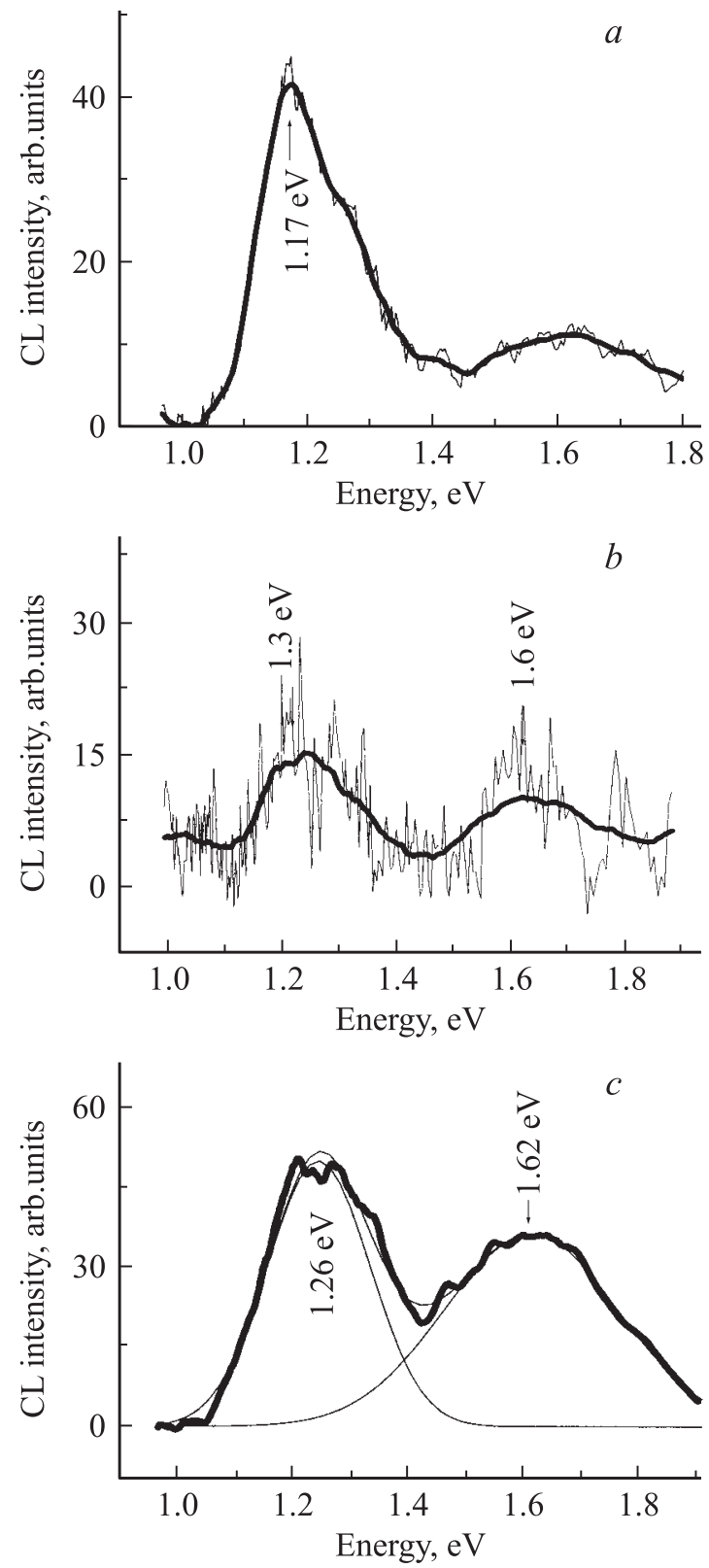

Figure 3. IR cathodoluminescence spectra of silicon oxidesilicon system: $a$ - silicon substrate under thick silicon oxide film, $b$ - porous silicon, $c$ - non-stoichiometry silicon oxide films with silicon nanoclusters of $4-10 \mathrm{~nm}$ size. 


\subsection{Distribution of point defects near the interface silicon oxide-silicon}

Fig. 1 shows cathodoluminescence spectra obtained on the silicon oxide wedge. The first spectrum is the one of a natural silicon oxide on silicon substrate after chemical etching. The second spectrum was obtained in the beginning of silicon oxide wedge on the silicon oxidesilicon interface. The next spectra were measured at two distances from the interface. The spectrum of natural silicon oxide consists of two cathodoluminescence bands at 2.0 and $2.7 \mathrm{eV}$ attributed to two type point defects ralated to oxygen deficit (twofold coordinated silicon $\mathrm{Si}=\mathrm{Si}$, and silicon-silicon bond, chain $\mathrm{Si}-\mathrm{Si}$ ). The first monolayers of silicon oxide on silicon are characterized by the same bands, but the intensity of the blue band $(\mathrm{Si}=\mathrm{Si})$ increases quicker compared with the green band $(\mathrm{Si}-\mathrm{Si})$. The red band at $1.9 \mathrm{eV}$ (non-bridged oxygen) appeared only at $0.1-0.2 \mu \mathrm{m}$ from interface. It is naturally because these defects are related to surplus of oxygen and therefore appear in silicon oxide films at some distance from the interface. The dependence of cathodoluminescent bands on distance is shown in Fig. 4. In this dependence, the thickness of silicon oxide film was taken into account. From the cathodoluminescence spectra we can see the spectral shift of the maximum of green band intensity. For natural oxide and for the interface the maxima of intensity are at

Table 1. Spectral characteristics of cathodoluminescence bands of silica

\begin{tabular}{l|c|c|c}
\hline $\begin{array}{c}\text { Band of } \\
\text { cathodoluminescence }\end{array}$ & Red & Green & Blue \\
\hline Time decay, $\mu \mathrm{s}$ & 28 & 5 & 5000 \\
Spectral position, eV & 1.9 & $2.0-2.4$ & 2.7 \\
FWHM, eV & 0.15 & $0.3-0.65$ & 0.35
\end{tabular}

Table 2. The main cathodoluminescence bands of silicon oxidesilicon system in visible and near IR region

\begin{tabular}{|c|c|c|}
\hline Spectral position, eV & FWHM, eV & Nature of spectral band \\
\hline 2.7 & 0.35 & $\begin{array}{l}\text { Twofold coordinated } \\
\text { silicon } \mathrm{Si}=\mathrm{Si}\end{array}$ \\
\hline $2.0-2.4$ & $0.25-0.8$ & $\begin{array}{l}\text { Silicon-silicon bond, } \\
\text { chains } \mathrm{Si}-\mathrm{Si}, \mathrm{Si}-\ldots-\mathrm{Si}\end{array}$ \\
\hline 1.9 & 0.15 & $\begin{array}{l}\text { Non-bridged oxygen } \\
\mathrm{Si}-\mathrm{O}\end{array}$ \\
\hline $1.4-1.9$ & $0.2-0.5$ & $\begin{array}{l}\text { Band-band transition } \\
\text { in silicon nanoclusters }\end{array}$ \\
\hline $1.26-1.4$ & $0.2-0.4$ & $\begin{array}{l}\text { Silicon with high contents } \\
\text { of oxygen or hydrogen }\end{array}$ \\
\hline 1.17 & 0.09 & $\begin{array}{l}\text { Band-band transition } \\
\text { in monocrystal silicon }\end{array}$ \\
\hline
\end{tabular}

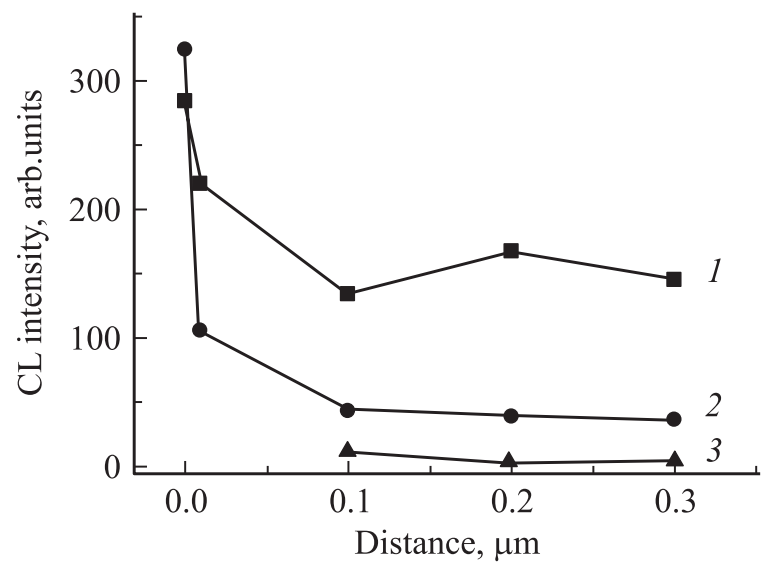

Figure 4. Dependence of cathodoluminescence bands intensity on depth of thermal silicon oxide film (from interface). $1,2,3$ - blue, green, and red bands.

$2.0-2.1 \mathrm{eV}$. The position of maximum shifts to $2.2-2.3 \mathrm{eV}$ at distance from the interface.

These results were compared with cathodoluminescence spectra obtained from the steps of silicon oxide. The samples were prepared by the second way. The thicknesses of silicon oxides steps were 10 and $20 \mathrm{~nm}$. These spectra look like the spectrum near the interface.

Fig. 5 shows the cathodoluminescence spectra of the same sample obtained at 5 and $10 \mathrm{keV}$. The electron beam at $5 \mathrm{keV}$ excites only silicon oxide film. At $10 \mathrm{keV}$ the interface gives the main contribution to luminescence. The spectrum at $5 \mathrm{keV}$ looks as usual spectrum of bulk silicon oxide. It consists of intensive band at $2.7 \mathrm{eV}$, band at $1.9 \mathrm{eV}$ and arm at $2.2 \mathrm{eV}$. The spectrum at $10 \mathrm{keV}$ related to interface consists of three bands. Contribution of the green band is the same as one of the blue band. This result agrees with the spectra obtained from the silicon oxide wedge near the interface.

The study of silicon oxide film on silicon in IR region showed the „blue" shift of emission band of silicon substrate and at the same time the appearance of bands at $1.4-1.8 \mathrm{eV}$. The shift of IR emission of silicon evidences the appearance of amorphous silicon layers with high concentration of oxygen. The bands at $1.4-1.8 \mathrm{eV}$ characterize the presence of silicon clusters near the interface. These results give a possibility for studying the process of silicon oxide growing on silicon.

\subsection{Characterization of silicon oxide-silicon interface during oxidation by cathodoluminescence method}

Different phases of oxidation were studied by cathodoluminescence method. At first it was silicon substrate polished by chemical way and passivated by hydrogen. This sample was kept at usual atmosphere. As a result the sample was covered with natural oxide. The next step was oxidation of this silicon during several days, after that - 

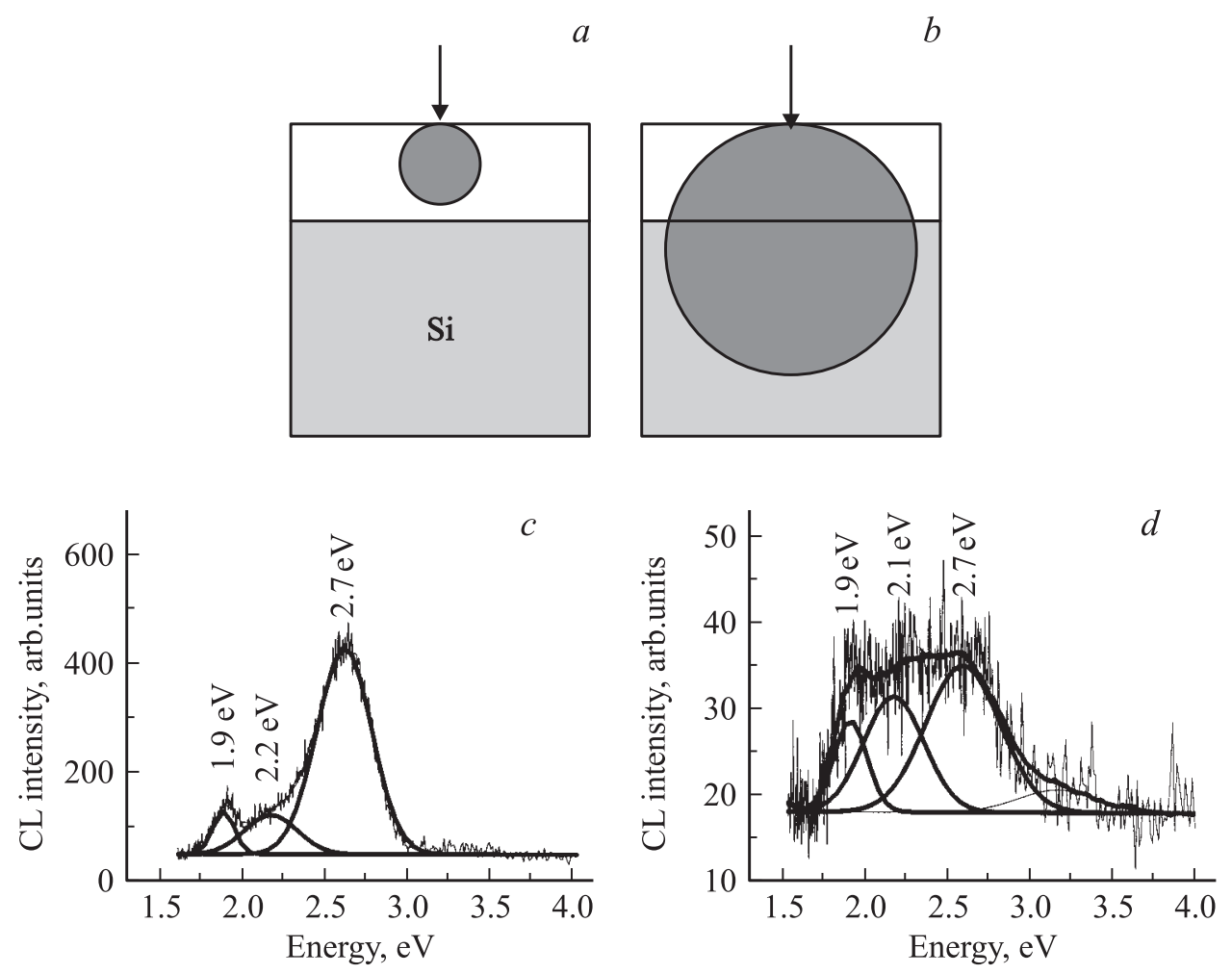

Figure 5. Penetration of electron beam with energy $5 \mathrm{keV}(a), 10 \mathrm{keV}(b)$ and cathodoluminescence spectra obtained at energy of electron beam $5 \mathrm{keV}(c), 10 \mathrm{keV}(d)$.

$a$
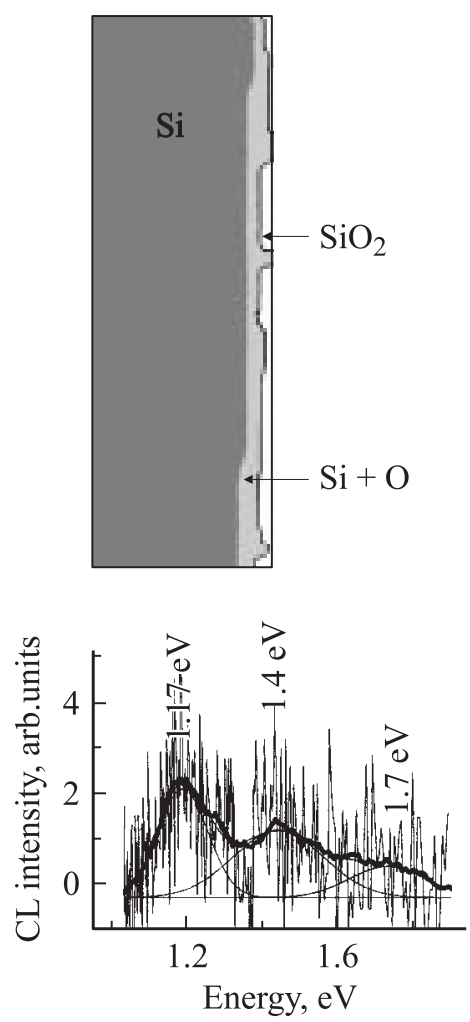

$b$
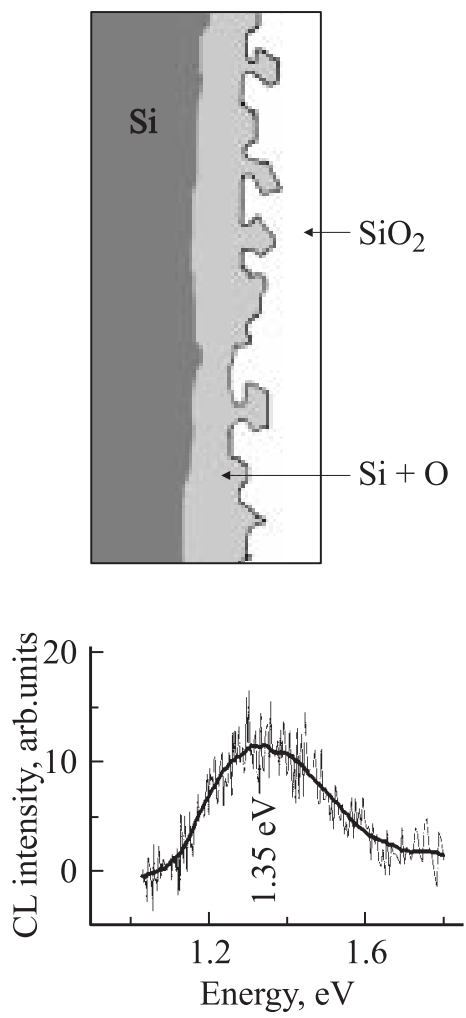

b 
thermal oxidation. The thickneses of silicon oxide and silicon oxide stoichiometry were studied by photoelectron spectroscopy method [12]. Cathodoluminescence spectra of silicon substrate passivated by hydrogen is characterized in IR region by typical band-band transitions in silicon $(1.17 \mathrm{eV})$ and week bands at 1.4 and $1.7 \mathrm{eV}$ related to silicon nanoclusters (Fig. 6). In visible range there were two bands at 2.7 and $2.0 \mathrm{eV}$ related to point defects (oxygen deficit). In several days the band at $1.26 \mathrm{eV}$ emerged in IR diapason. In visible region the bands were at the same spectral positions but their intensity increased. In the case of the thick silicon oxide film (more than $0.1 \mu \mathrm{m}$ ) the cathodoluminescence spectra of silicon oxide film on silicon have the intensive band in IR region at $1.17 \mathrm{eV}$ and three bands at 1.9, 2.2 and $2.7 \mathrm{eV}$ in visible range.

These results showed that the first step of oxidation is the appearance of layers of amorphous silicon with high concentration of impurities of oxigen or hydrogen on the surface of silicon substrate. It leads to appearance of the luminescence band at $1.26-1.35 \mathrm{eV}$. The rapidity of oxidation depends on the presence of different types of defects on the silicon substrate. This process leads to deformation of the interface and the formation of silicon nanoclusters near the interface. The cathodoluminescence gives the possibility for investigating this process.

\subsection{Characterization of natural silicon oxide on silicon by cathodoluminescence method}

Cathodoluminescence method permits to compare the properties of natural silicon oxide films depending on the type of silicon conductivity. The basic difference between silicon oxide films grown on $n$ - and $p$-silicon (doped with boron or phosphorus) is related with the segregation coefficient of activators in silicon oxide. During the oxidation boron is dissolved in silicon oxide. As a result the layers of silicon near the interface contain smaller amount of boron compared with silicon substrate. In silicon oxide the concentration of boron near the interface is rather high. It generates the increase of point defects in silicon oxide near the interface because boron in silicon oxide is characterized by valence state -3 and occupies positions of silicon. On the contrary, phosphorus from $n$-silicon has low solubility in silicon oxide. That is why the layer of silicon near the interface is characterized by high concentration of phosphorus near the interface and silicon oxide contains less point defects near the interface. Cathodoluminescence spectra in IR region demonstrate superior spectral shift for $n$-silicon and the intensity of the band related to silicon nanoclusters is higher. Comparison of cathodoluminescence spectra in visible range shows the ,red“ shift of the green band for $p$-silicon (1.9 eV for $p$-silicon compared $2.1 \mathrm{eV}$ for $n$-silicon). This shift can be explained by the formation of silicon chains near the interface.

\section{Conclusion}

Cathodoluminescence method permits to characterize the $\mathrm{SiO}_{2} / \mathrm{Si}$ interface, the change of its properties during oxidation and the influence of the type of silicon conductivity on the properties of $\mathrm{SiO}_{2} / \mathrm{Si}$ interface. This study has shown that:

- cathodoluminescence spectra of silicon oxide are characterized by three bands, at $1.9,2.0-2.4$ and $2.7 \mathrm{eV}$; the band at $2.0-2.4 \mathrm{eV}$ is related to silicon-silicon bond (chain $\mathrm{Si}-\mathrm{Si}, \mathrm{Si}-\ldots-\mathrm{Si}$ and $\mathrm{Si}$-ring); the spectral position and the FWHM of this band define the length of $\mathrm{Si}-\mathrm{Si}$ chains, its concentration;

- cathodoluminescence spectra of silicon oxide near the interface is characterized by the bands related to twofold coordinated silicon $(\mathrm{Si}=\mathrm{Si})$ at $2.7 \mathrm{eV}$ and silicon-silicon bond (chain $\mathrm{Si}-\mathrm{Si}, \mathrm{Si}-\ldots-\mathrm{Si}$ ) at $2.0-2.4 \mathrm{eV}$; the ,red“" shift of this band is related to elongation of $\mathrm{Si}$ chains in silica;

- the first phase of silicon oxidation is the formation of amorphous silicon layers on the surface of silicon with higher content of oxygen or hydrogen impurities and the appearance of silicon clusters in thick silicon oxide.

\section{References}

[1] M.V. Zamoryanskaya, S.G. Konnikov, A.N. Zamoryanski. Instruments and Experimental Techniques, 47, 477 (2004).

[2] H.-J. Fitting, T. Barfels, A.N. Trukhin, B. Schmidt, A. Gulans, A. von Czarnowski. J. Non-Cryst. Sol., 303, 218 (2002).

[3] L.N. Skuya, A.R. Silin. Phys. Status Solidi A, 70, 43 (1982).

[4] L.N. Skuya, A.N. Streletsky, A.B. Pakovich. Sol. St. Commun., 50, 1069 (1984).

[5] L.A. Bakaleinikov, M.V. Zamoryanskaya, E.V. Kolesnikova, V.I. Sokolov, E.Yu. Flegontova. Phys. Sol. St., 46 (6), 1018 (2004).

[6] M. Takeguchi, K. Furuya, K. Yoshinara. Jap. J. Appl. Phys., Pt. 1, 38 (12B), 7140 (1999).

[7] M.V. Zamoryanskaya, V.I. Sokolov. Sol. St. Phenomena, 108-109, 649 (2005).

[8] V.A. Gritsenko. Structure and electronic properties of amorphous dielectrics in silicon MIS structures (Novosibirsk, Nauka, 1993) p. 278.

[9] Roushdey Salh, A. von Czarnowski, M.V. Zamoryankaya, E.V. Kolesnikova, H.-J. Fitting. Phys. Status Solidi A, 203 (8), 2049 (2006).

[10] M.S. Bresler, I.N. Yassievich. Semiconductors, 27, 475 (1993).

[11] C. Diaz-Guerra, D.A. Kurdyukov, J. Piqueras, V.I. Sokolov, M.V. Zamoryanskaya. J. Appl. Phys., 89 (5), 2720 (2001).

[12] M.V. Zamoryanskaya, V.I. Sokolov, V. Plotnikov. Appl. Surf. Sci., 234, 214 (2004).

Редактор Л.В. Шаронова 